\title{
On the Analytical Models of Confined High-Strength Steel-Fiber Concrete
}

\author{
Sutarno*, Antonius, Sumirin \\ Faculty of Engineering, Universitas Islam Sultan Agung, Semarang, Indonesia
}

Received February 15, 2021; Revised April 14, 2021; Accepted May 10, 2021

\section{Cite This Paper in the following Citation Styles}

(a): [1] Sutarno, Antonius, Sumirin, "On the Analytical Models of Confined High-Strength Steel-Fiber Concrete," Civil Engineering and Architecture, Vol. 9, No. 3, pp. 869 - 873, 2021. DOI: 10.13189/cea.2021.090328.

(b): Sutarno, Antonius, Sumirin (2021). On the Analytical Models of Confined High-Strength Steel-Fiber Concrete. Civil Engineering and Architecture, 9(3), 869 - 873. DOI: 10.13189/cea.2021.090328.

Copyright $\odot 2021$ by authors, all rights reserved. Authors agree that this article remains permanently open access under the terms of the Creative Commons Attribution License 4.0 International License

\begin{abstract}
Generally, confinement models of the steel-fiber concrete were very ductile because the fiber has a significant influence on the increase of the concrete deformability. Nevertheless, the existing steel fibrous confined models now have significant differences between each other, especially the peak stress value and post peak behavior. It is some of the different reviewed design parameters that affect the stress-strain equation of developed confined steel-fiber concrete. This paper investigated the existing confinement models to evaluate pre- and post-peak behavior of experimental results of confined steel fiber concrete for square sections. This paper has discussed models of existing steel fibrous concrete restraints compared to the results of experiments. In general, it can be concluded that the Hsu model is able to predict the best $\mathrm{K}$ value and ascending branch curve toward the experiment results. However, in the unfettered concrete ductility of the descending branch curve, the predicted values of $\varepsilon_{c c}^{\prime}$ and $\varepsilon_{50 \mathrm{cc}}$, it can be said that all the models reviewed are still not able to model properly. The difference is mainly due to the parameters reviewed to lower the restraints of each model are not the same. The comparison results presented in this paper recommend the need for more complete experimental research with broader parameters such as cross-sectional shape, fiber ratio, and restraint bone characteristics, in order to lower the model of restraint more generally.
\end{abstract}

Keywords Steel-Fiber Concrete, Confinement Models, Stress-Strain, Ductility

\section{Introduction}

Steel fibrous concrete technology has grown rapidly and popularly in the last decade. Steel fibrous concrete is known to have excellent matrix bonding, high cracking firmness, good attachment property and ductile [1,2]. In addition, the material also has good fire resistance $[3,4]$. Due to materially ductile, steel fibrous concrete is very useful to be used in earthquake-resistant structures, especially in column structure components.

As known, column structure plays a central role in maintaining the stability of structures such as building. In earthquake-resistant building structure column structure should have adequate ductility. If the fibrous steel column is installed bone restraint with a certain volumetric ratio, then the ductility will certainly increase significantly. To determine the security level of the column structure a model of restraint is required [5]. As with normal concrete (without fiber) high quality where the analysis of the fastener joint has also been widely researched [6,7], on steel fibrous concrete also continues to develop $[8,9,10]$. Similarly, the model of restraint continues to be developed but until now there is no model that is generally widely accepted as a reference for planning. These restraint models need to be evaluated in depth in order to find out the sensitivity of each model in modeling voltage-strain behavior before and after peak.

\section{Objective and Scope}

This paper presents the comparison of restraint model especially for predicting the behavior of high-quality 
unfettered steel fibrous concrete. The comparison variations include voltage-strain behavior, increased strength of unfettered concrete $(\mathrm{K})$, unfettered concrete peak strain $\left(\varepsilon_{\mathrm{cc}}^{\prime}\right)$ and unfettered concrete strain value when concrete voltage drops from peak voltage by $50 \%\left(\varepsilon_{50 \mathrm{cc}}\right)$. High quality concrete in this paper has a press strength of more than $50 \mathrm{MPa}$. The steel-sided restraint models discussed were the Ganesan \& Murthy proposal model [11], the Campione proposal model [12] and the Hsu \&amp; Hsu proposal model [ 13].

\subsection{Confinement Models of Steel-Fiber Concrete}

\subsubsection{Model by Ganesan}

Ganesan and Murthy [11] proposed a model of restraint for steel fibrous concrete based on the test results of a number of unfettered concrete test objects by reviewing the reinforcing parameters and the percentage ratio of steel fibers by $1.5 \%$. In his experiments, Ganesan used a fiber aspect ratio of 70 . The increased strength of the unfettered concrete $(\mathrm{K})$ is influenced by the hard press of the concrete $\left(\mathrm{f}_{\mathrm{c}}^{\prime}\right)$ ratio and the melting voltage of the reinforcing bone $\left(\rho_{\mathrm{s}}\right.$ and $f_{y}$ ) as written in the equation (1).

$$
K=1+\frac{\rho_{s} f_{y h}}{f_{c}^{\prime}}
$$

The peak strain of unfettered concrete $\left(e_{p}\right)$ is influenced by the $K$ value, fiber percentage and fiber shape factor $\left(A_{p}\right)$ as presented in the equation (2).

$$
e_{p}=0.002 K\left(1+V_{f} A_{p}\right)
$$

The voltage-strain curves in pre- and post-peak are written on equations (3) and (4).

$$
\begin{aligned}
& \mathrm{f}=\mathrm{Kf}^{\prime}{ }^{\prime}{ }^{\prime} \frac{\mathrm{A}_{1}\left(\mathrm{e} / \mathrm{e}_{\mathrm{p}}\right)+\mathrm{B}_{1}\left(\mathrm{e} / \mathrm{e}_{\mathrm{p}}\right)^{2}}{1+\mathrm{C}_{1}\left(\mathrm{e} / \mathrm{e}_{\mathrm{p}}\right)+\mathrm{D}_{1}\left(\mathrm{e} / \mathrm{e}_{\mathrm{p}}\right)^{2}} \\
& \mathrm{f}=\mathrm{Kf}^{\prime}{ }^{\prime} \frac{\mathrm{A}_{2}\left(\mathrm{e} / \mathrm{e}_{\mathrm{p}}\right)+\mathrm{B}_{2}\left(\mathrm{e} / \mathrm{e}_{\mathrm{p}}\right)^{2}}{1+\mathrm{C}_{2}\left(\mathrm{e} / \mathrm{e}_{\mathrm{p}}\right)+\mathrm{D}_{2}\left(\mathrm{e} / \mathrm{e}_{\mathrm{p}}\right)^{2}}
\end{aligned}
$$

\subsubsection{Model by Hsu \& Hsu}

Hsu \& Hsu proposes a high-quality voltage-strain equation of unfettered steel fibrous which is the result of testing of concrete test objects with variations in steel fibre volume ( 0.5 percent, 0.75 percent and 1 percent), space and volumetric ratio of reinforcing joints. The voltage-strain model is expressed as follows:

$$
\eta=\frac{n \beta x}{n \beta-1+x^{n \beta}}
$$

Where

$$
\eta=\frac{f_{c}}{f_{c c}^{\prime}}
$$

$$
x=\frac{\varepsilon_{c}}{\varepsilon_{c c}^{\prime}}
$$

And

$$
\beta=\left[\frac{f_{3}^{\prime}}{A}\right]+C
$$

Hsu \& Hsu determined that for fibre volume of 0.5 percent, $\beta$ and $C$ values are 8.70 and 2.61. Furthermore, for fibre content of 0.5 percent, the voltage and strain of unfettered concrete peaks are estimated as follows:

$$
\begin{gathered}
f^{\prime}{ }_{c c}=197.95 \rho+f^{\prime}{ }_{c} \quad \text { (in ksi) } \\
\varepsilon^{\prime}{ }_{c c}=0.2252 \rho+\varepsilon_{o}
\end{gathered}
$$

Based on the equations (9) and (10), the peak voltage and strain of unfettered concrete peaks depend on the ratio of reinforcing joints and strong press of concrete without restraints.

\subsubsection{Model by Campione}

The restraint model by Campione is a modification of the Hsu \& Hsu model, where several parameters that determine the slope of the voltage-strain curve are modified. In full the model is as follows.

Ascending branch:

$$
\frac{\sigma}{f^{\prime}{ }_{c}}=\frac{\beta\left(\varepsilon / \varepsilon_{0}\right)}{\beta-1+\left(\varepsilon / \varepsilon_{0}\right)^{\beta}}
$$

Descending branch:

$$
\begin{gathered}
\frac{\sigma}{f^{\prime}{ }_{c}}=\eta_{d} \exp \left[-k_{d}\left(\frac{\varepsilon}{\varepsilon_{o}}-x_{d}\right)^{\lambda}\right] \\
\beta=A+B(R I)^{c}
\end{gathered}
$$

where $\mathrm{A}=0.5811, \mathrm{~B}=1.93$ dan $\mathrm{C}=-0.740$

$$
\beta=\frac{E_{c}}{E_{c}-\left(f^{\prime}{ }_{c} / \varepsilon_{0}\right)}
$$

The increased strength and strain of unfettered concrete are shown in the equations (15) and (16).

$$
\begin{aligned}
& \frac{f^{\prime}{ }_{c c}}{f^{\prime}{ }_{c}}=1+2.1\left(k_{e} \frac{f_{l}}{f^{\prime}{ }_{c}}\right)^{0.7} \\
& \frac{\varepsilon_{c c}}{\varepsilon_{o}}=1+5 k_{1}\left(k_{e} \frac{f_{l}}{f^{\prime}{ }_{c}}\right)^{0.7}
\end{aligned}
$$

\subsection{Comparative Study of Confinement Models and Discussion}

The model of steel fibrous restraints that have been described above are further compared to each other, including their comparisons with the experiments of unfettered steel fibrous concrete. The experimental data were taken from the test results by Antonius [14], where 
selected specimens that have a concrete press strength of $50 \mathrm{MPa}$ or more. According to the experimental data, the volume of steel fiber is 0.5 percent, and the aspect ratio of fiber is about 45 . The effectiveness value of restraint refers to the concept proposed by Mander et al. $[15,16]$.

\subsection{Strain-Voltage Behaviours}

Figure 1 is a voltage-strain ratio curve of unfettered concrete to a concrete press strength of $51 \mathrm{MPa}$, with a variation in the volumetric ratio of reinforcing joints. Based on the figure, it appears that the Hsu model is closer to the results of experiments in the ascending branch area, although it has significant differences in the descending branch area. From these three models, it appears that the ascending branch curve of the Ganesan model is the steepest compared to other curves where it indicates that the Ganesan model has the highest initial rigidity. However, on the descending branch curve, the Ganesan model is concave with a slope curve that tends to ramp. These descending branch curves differ greatly from the same curves for Campione models that look very ductile. Significant differences in concrete voltage-strain behaviour between the Ganesan model and the experiment results also results from a review of fibre percentage and the ratio of different fibre aspects. Of the three existing restraint models, the Hsu model has a predicted peak voltage of unfettered concrete $\left(f^{\prime}{ }_{c c}\right)$ which is the closest to the $f_{c c}$ value of the experiment results.

Comparison of other voltage-strain behaviour is shown in Figure 2, where the concrete pressure strength is higher at 71.2 MPa. Similar to the comparison in Figure 1 above, the predicted f'cc value and ascending branch curve based on the Hsu model are the closest to the experiment results. However, the descending branch behaviour of the three models had significant differences with the results of the experiments.

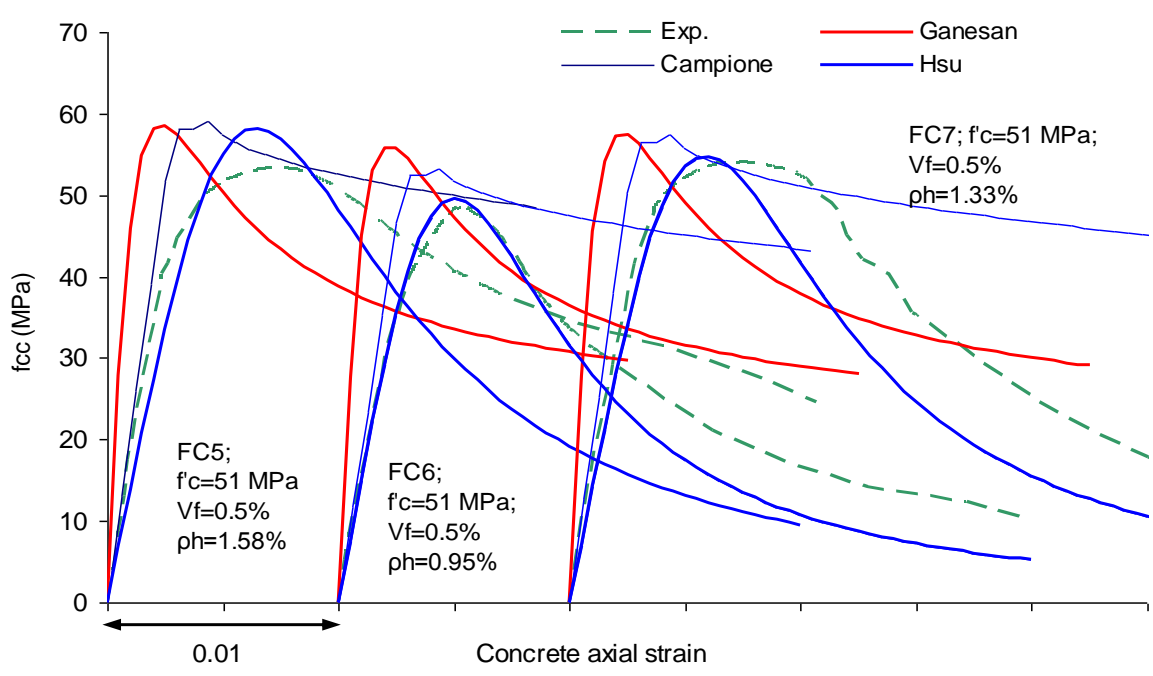

Figure 1. Comparison of strain-voltage behaviors for $f^{\prime}{ }_{c}=51 \mathrm{MPa}$

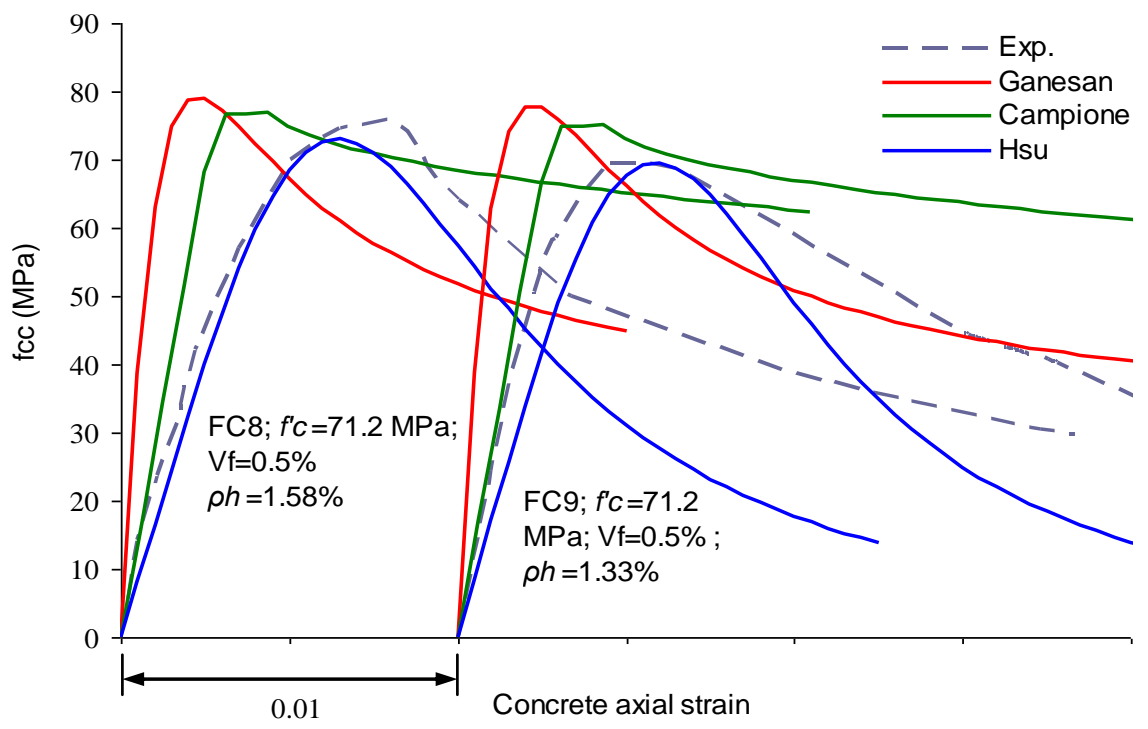

Figure 2. Comparison of strain-voltage behaviors for $f^{\prime}{ }_{c}=71.2 \mathrm{MPa}$ 
Table 1. Values of $K, \varepsilon_{c c}^{\prime}$ dan $\varepsilon_{50 c c}$

\begin{tabular}{ccccccccccccc}
\hline \multirow{2}{*}{ Specimens } & \multicolumn{3}{c}{ Exp. } & \multicolumn{3}{c}{ Ganesan } & \multicolumn{3}{c}{ Campione } & \multicolumn{3}{c}{ Hsu } \\
& $K$ & $\varepsilon_{c c}^{\prime}$ & $\varepsilon_{50 c c}$ & $K$ & $\varepsilon_{c c}^{\prime}$ & $\varepsilon_{50 c c}$ & $K$ & $\varepsilon_{c c}^{\prime}$ & $\varepsilon_{50 c c}$ & $K$ & $\varepsilon_{c c}^{\prime}$ & $\varepsilon_{50 c c}$ \\
\hline FC5 & 1.23 & 0.008 & 0.028 & 1.13 & 0.003 & 0.023 & 1.36 & 0.004 & - & 1.34 & 0.007 & 0.015 \\
\hline FC6 & 1.12 & 0.005 & 0.016 & 1.08 & 0.003 & - & 1.23 & 0.004 & - & 1.14 & 0.005 & 0.012 \\
\hline FC7 & 1.25 & 0.008 & 0.020 & 1.11 & 0.003 & 0.003 & 1.32 & 0.004 & - & 1.26 & 0.006 & 0.014 \\
\hline FC8 & 1.25 & 0.008 & 0.02 & 1.09 & 0.003 & 0.012 & 1.27 & 0.004 & - & 1.21 & 0.007 & 0.014 \\
FC9 & 1.15 & 0.006 & 0.021 & 1.08 & 0.003 & - & 1.24 & 0.004 & - & 1.15 & 0.006 & 0.013 \\
\hline
\end{tabular}

Table 2. Comparison of analytical results toward experiments

\begin{tabular}{|c|c|c|c|c|c|c|c|c|c|}
\hline \multirow[b]{2}{*}{ Specimens } & \multicolumn{3}{|c|}{ Ganesan } & \multicolumn{3}{|c|}{ Campione } & \multicolumn{3}{|c|}{ Hsu } \\
\hline & $K_{\text {anal }} / K_{\text {exp }}$ & $\begin{array}{l}\varepsilon_{\text {cc(anal. })}^{\prime} \\
\varepsilon_{\text {cc(exp.) }}^{\prime}\end{array}$ & $\begin{array}{l}\varepsilon_{50 \mathrm{cc}(\text { anal. })} / \\
\varepsilon_{50 \mathrm{cc} \text { (exp.) }}\end{array}$ & $K_{\text {anal }} / K_{\text {exp }}$ & $\begin{array}{l}\varepsilon_{\text {cc(anal. })}^{\prime} / \\
\varepsilon_{\text {cc(exp.) }}^{\prime}\end{array}$ & $\begin{array}{l}\varepsilon_{50 \mathrm{cc}(\text { anal. })} / \\
\varepsilon_{50 \mathrm{cc}(\text { exp.) }}\end{array}$ & $K_{\text {anal }} / K_{\text {exp }}$ & $\begin{array}{l}\varepsilon_{\text {cc(anal.) }}^{\prime} / \\
\varepsilon_{\text {cc(exp.) }}\end{array}$ & $\begin{array}{l}\varepsilon_{50 \mathrm{cc}(\text { anal. })} / \\
\varepsilon_{50 \mathrm{cc} \text { (exp.) }}\end{array}$ \\
\hline FC5 & 0.92 & 0.37 & 0.80 & 1.11 & 0.59 & - & 1.09 & 0.87 & 0.53 \\
\hline FC6 & 0.96 & 0.51 & - & 1.10 & 0.84 & - & 1.02 & 0.98 & 0.71 \\
\hline FC7 & 0.89 & 0.36 & 1.12 & 1.06 & 0.57 & - & 1.01 & 0.79 & 0.69 \\
\hline FC8 & 0.87 & 0.34 & 0.58 & 1.02 & 0.54 & - & 0.97 & 0.81 & 0.68 \\
\hline FC9 & 0.94 & 0.46 & - & 1.08 & 0.75 & - & 1.00 & 1.05 & 0.58 \\
\hline
\end{tabular}

\subsection{Evaluation of $K, \varepsilon_{c c}$ and $\varepsilon_{50 c c}$ Value toward Experiment Result}

Table 1 is the $\mathrm{K}, \varepsilon_{\mathrm{cc}}^{\prime}$ and $\varepsilon_{50 \mathrm{cc}}$ values from the result of experiments and models of restraints. When viewed the experimental results (Table 2), the $\mathrm{K}$ value based on the Ganesan model differs by at least 4 percent (specimen FC6) and a maximum of 13 percent (specimen FC8). A significant difference between predictions based on the Ganesan model is the value $\varepsilon_{\text {cc }}^{\prime}$ (between 50 to 60 percent) even for $\varepsilon_{50 \mathrm{cc}}$ value prediction it turns out that two specimens are unpredictable (specimen FC6 and FC9). These results show that there are significant differences in the ductility of high quality unfettered fibrous concrete.

On the other hand, the Campione model predicts a slightly better experimental $\mathrm{K}$ value than the Ganesan model above. Deviation of $\mathrm{K}$ value based on Campione model ranges from 2 percent to 11 percent. Similarly, in terms of predicted $\varepsilon_{\text {cc }}^{\prime}$, the maximum differs by 46 percent (specimen FC8). The value of $850 \mathrm{cc}$ based on the Campione model is unpredictable, because in the post-peak response the Campione model is very ductile and only experienced a meaningless decrease in strength. This is in line with the voltage-strain behavior of the descending branches as shown in Figures 1 and 2 above.

Compared to the two models of restraints above, the proposed Hsu model is able to predict the best $\mathrm{K}$ value of the experiment results. The biggest difference is only 9 percent, even in specimen FC9 the predicted value is very precise. Similarly, in the comparison of $\varepsilon_{\mathrm{cc}}^{\prime}$ values where the difference between models and experiments is only 5 percent to 21 percent. The Hsu model is also able to predict relatively better $\varepsilon_{50 \mathrm{cc}}$ values where predictions of different experiment results are maximum 42 percent (specimen FC9).

\section{Conclusions}

This paper has discussed the models of existing steel fibrous concrete restraints compared to the results of experiments. In general, it can be concluded that the Hsu model is able to predict the best $\mathrm{K}$ value and ascending branch curve toward the experiment results. However, in the unfettered concrete ductility of the descending branch curve, the predicted values of $\varepsilon_{\mathrm{cc}}^{\prime}$ and $\varepsilon_{50 \mathrm{cc}}$, it can be said that all the models reviewed are still not able to model properly. The difference mainly results from the parameters reviewed to lower the restraints of each model are not the same. The comparison results presented in this paper recommend the need for more complete experimental research with broader parameters such as cross-sectional shape, fiber ratio, and restraint bone characteristics, in order to lower the model of restraint more generally.

\section{REFERENCES}

[1] Lee, S.C., Oh, Joung-Hwan, Cho, Jae-Yeol.: Compressive behavior of fiber-reinforced concrete with end-hooked steel fibers. Materials, 8(4), 1442-1458 (2015).

[2] Jansson, A., Lofgren, I., Lundgren, K., Gyltoft, K.: Bond of reinforcement in self-compacting steel-fibre-reinforcement 
concrete. Magazine of Concrete Research, 64(7), 617-630 (2012).

[3] Antonius, Widhianto, A., Darmayadi, D., Asfari, G.D.: Fire resistance of normal and high-strength concrete with contains of steel fibre. Asian Journal of Civil Engineering, 15(5), 655-669 (2014).

[4] Antonius, Purwanto, Harprastanti, P.: Experimental study of the flexural strength and ductility of post burned steel fiber rc beams. International Journal of Technology, 10(2), 428-437 (2019).

[5] Paultre, P., Eid, R., Langlois, Y., Lévesque, Y.: Behavior of steel fiber-reinforced high-strength concrete columns under uniaxial compression. Journal of Structural Eng., 136(10), 1225-1235 (2010).

[6] Antonius: Studies on the provisions of confining reinforcement for high-strength concrete column. Procedia Engineering, 95, 100-111 (2014).

[7] Antonius, Imran, I., Setiyawan, P.: On the confined high-strength concrete and need of future research. Procedia Engineering, 171, 121-130 (2017).

[8] Cholida, N.F.F., Antonius, Ni'am, F.: A parametric study of confinement effects to the interaction diagram of $\mathrm{p}-\mathrm{m}$ for high-strength concrete columns. Journal of Advanced Civil and Environmental Engineering, 1(1), 30-37 (2018).

[9] Amariansah, W., Karlinasari, R.: The Influence of Steel Fiber on the Stress-Strain Behavior of Confined Concrete. Journal of Advanced Civil and Environmental Engineering, 2,(1), 46-52 (2019).

[10] Han, A.L, Antonius, Okiyarta, A.W.: Experimental study of steel fiber reinforced concrete beams with confinement. Procedia Engineering, 125, 1030-1035 (2015).

[11] Ganesan, N., Murthy, J.V. Ramana: Strength and behavior of confined steel fiber reinforced comcrete columns. ACI Materials Journal 87(3), 221-227 (1990).

[12] Campione, G.: The effect of fibers on the confinement models for concrete columns. Canadian Journal of Civil Engineering 29, 742-750 (2002).

[13] Hsu, L.S., Hsu, C.T.: Stress-strain behavior of steel-fiber high-strength concrete under compression. ACI Structural Journal, 91(4), 448-457 (1994).

[14] Antonius: Strength and energy absorption of high-strength steel fiber concrete confined by circular hoops. International Journal of Technology, 6(2), 217-226 (2015).

[15] Mander, J.B., Priestley, M.J.N., Park, R.: Theoritical stress-strain model for confined concrete. Journal of Structural Engineering, 114(8), 1804-1824 (1988).

[16] S. Rahman, "Investigation on Mechanical Strength of Concrete Using Steel Bottle Caps as Fiber," Civil Engineering and Architecture, Vol. 7, No. 1, pp. 1 - 4, 2019. DOI: $10.13189 /$ cea.2019.070101. 